Article

\title{
End-of-Life Strategies for Used Mobile Phones Using Material Flow Modeling
}

\author{
Kuniko Mishima ${ }^{1, *}$, Michele Rosano ${ }^{2}$, Nozomu Mishima ${ }^{3}$ and Hidekazu Nishimura ${ }^{1}$ \\ 1 Graduate School of System Design and Management, Keio University, Yokohama 223-8526, Japan; \\ h.nishimura@sdm.keio.ac.jp \\ 2 Sustainable Engineering Group, Curtin University, Perth, WA 6845, Australia; M.Rosano@curtin.edu.au \\ 3 Graduate School of Engineering and Resource Science, Akita University, Akita 010-8502, Japan; \\ nmishima@gipc.akita-u.ac.jp \\ * Correspondence: mishima-ssdb2172@jcom.zaq.ne.jp; Tel.: +81-29-827-1171
}

Academic Editor: William Bullock

Received: 20 January 2016; Accepted: 2 February 2016; Published: 6 February 2016

\begin{abstract}
In order to secure valuable materials and to establish better circular economy practice, new legislation to promote recycling of small-sized e-waste including used mobile phones started in April 2013, in Japan. In order to consider appropriate methods to reduce material usage in mobile phone production, an examination of appropriate strategies in handling used mobile phone products is warranted. This paper investigates an analysis of material flow model for used mobile phones. Then, by analyzing the model, it tries to find suitable strategies to reduce the material consumption associated with mobile phone production and consumption. Although material recycling is an important strategy in Japan, other waste management options exist. This research indicates which factors are keys in reducing material consumption and $\mathrm{CO}_{2}$ emission, and establishing resource efficient production. The study concludes that "domestic product reuse" and "official recycling networks" are equally good in reducing the consumption of virgin materials associated with mobile phone production. However, in doing so, it is necessary to establish a system in which consumers can properly return their used mobile phones for recycling. Such an end-of-life waste management system can reduce both waste and resource consumption and the environmental impacts associated with increasing mobile phone production. Further research investigating the value of increasing the product reuse rate and the collection return rate for mobile phones is also warranted.
\end{abstract}

Keywords: used mobile phone; end-of-life option; material recycling; product reuse; material consumption; $\mathrm{CO}_{2}$ emission; sensitivity analysis

\section{Introduction}

Japan is not a resource-rich country, with most natural resources needing to be imported from other countries. However, manufactured waste in Japan is increasingly seen as being an important source of resource material given that end-of-life appliances typically stay in the domestic market many years after their "useful life" has ended. Such end-of-life (EOL) products have become a source of material for urban mining [1,2]. For example, $16 \%$ of the world reserve of gold exists in Japan [3] as urban mining material. The importance and effectiveness of utilizing precious metals, critical metals and common metals in urban mines has been well noted in previous research [4]. From April 2013, legislation to promote the recycling of small-sized e-waste started in Japan in order to recover currently unutilized but valuable resources [5] in advance of the enforcement of the legislation. This legislation only focuses on the material recycling associated with consumer behavior with used mobile phones [6], where typically a certain volume of small-sized e-waste products/materials like mobile phones at 
end-of-life are re-utilized as second-hand products with the same functionality as the original products. This second-hand use needs to be taken into account in this smart phone era with increasing pressure on resource efficiency and scarcity. Previous research by Mishima (2015) [7] has shown the value and importance of motivating consumers to put their used products in recycling bins to provide second-hand use for these end-of-life products. However this study has also highlighted the need for new systems to be put in place to assist with increasing the recyclability of used mobile phones in Japan.

In order to establish a consumer-friendly recycling system, more understanding of Japanese consumer behavior for mobile phones is needed These investigations required a better understanding of the "movement" of these end-of-life products through a modeling and analysis of the material flow. Previous research [8-10] and a public report [11] have investigated the material flow of some used electronic equipment such as Personal Computers and mobile phones, in Japan and in other countries. Although these studies have been helpful in clarifying some of the current problems in consumer recycling systems, situations can be different in nowadays "smartphone era." A new investigation based on the current situation in Japan is necessary. One of the studies [12] focused on environmental impacts of recycling considering material compositions of mobile phones. Another study [13] shows factors to affect statistics regarding material recycling of WEEE combining material flow analysis and structural analysis. These previous studies have mainly focused on material recovery from used products. However, material recycling is not the only end-of-life waste management option. Such used products can become stocks of potential second-hand products and their associated reusable components. As a result, further comprehensive studies are necessary to investigate other recycling strategies for sustainable end-of-life waste management options for e-waste products like mobile phones. There is also a study [14] that discusses appropriate end-of-life management strategies based on scenario analysis. This study is also driven by a similar motivation and takes a different approach. A simple sensitivity analysis is chosen to analyze the illustrated model.

The mobile phone is one of the most important e-waste products in terms of its recycling potential given the amount of critical metals they contain [5]. If all Japanese used mobile phones were collected and recycled, $2 \%-3 \%$ of (Japanese) annual consumption of gold, silver and palladium could be reduced [5]. This amount is not very large, but should be considered in the context of potential economic and political changes in resource-exporting countries. It is well-known that there are behavioral challenges with the collection of used mobile phones via recycling bins. Mishima (2015) [7] noted the potential for financial incentives (reward money) in encouraging the placement of used mobile phones in recycling bins. However, this same research also suggested that a financial incentive for encouraging the placement of the used mobile phone in the recycling bin was unlikely to encourage second hand product use [6]. Mishima (2015) suggested that the total residual value of recoverable materials in a used mobile phone was only around 100 JPY [15]. In order to build a sustainable recycling system for mobile phones, it is considered necessary to recover larger residual values from used products. Since resource recovery and efficiency are increasingly becoming an economic imperative for industrialized countries [16], producers are increasingly having to consider how to reduce the usage of virgin materials and the recovery of waste materials in their production activities. The objective of this study is to investigate the current material flow of used mobile phones to provide an enhanced understanding of the potential EOL waste management options for mobile phones in Japan.

\section{Material Flow Modeling of Used Mobile Phone}

\subsection{Collection of Used Mobile Phone}

This paper investigates the material flow of used mobile phones currently in Japan. The collection of used mobile phones in Japan has been previously investigated by the MRN (mobile phone recycle network) [17]. This organization is a collaboration between private enterprises and collects used 
phones for material recycling. Figure 1. illustrates the material flow model of used mobile phones in Japan in 2010, focusing on the primary organizations collecting the phones. Except for illegal dumping and hibernation, the three main collectors of used mobile phones are the MRN, other similar collectors and local government. Only approximately $20 \%$ of end-of-life mobile phones in Japan are collected by the MRN. The remaining $80 \%$ are either "hibernated" or collected by other organizations. Once the used phones are collected by other organizations, it is difficult to account for their material flows. For the purposes of this research, the MRN process is assumed to provide an indicative value for the enhanced recycling of mobile phones in Japan, assuming that recovery rates are able to be significantly increased. It is then considered possible to extrapolate the potential for improving end-of-life strategies of used mobile phones in Japan in both reducing the mobile phones sent to landfill and in improving both their domestic recycling and export potential.

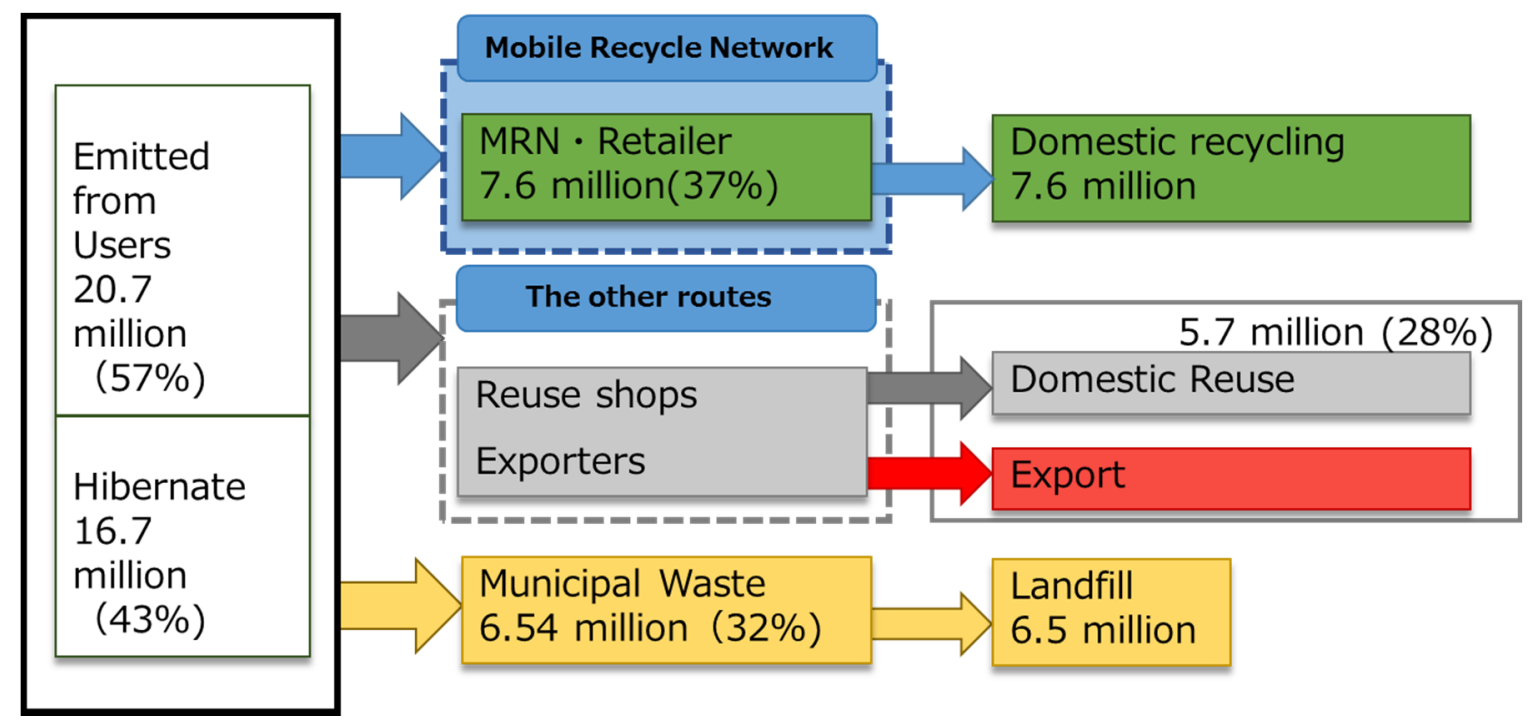

Figure 1. Overall flow of the used mobile phones in Japan in 2010 [18].

As is shown in Figure 1, 28\% of mobile phones will be reused in domestic or international markets, $37 \%$ will be recycled through the MRN and $32 \%$ end up in landfill. As discussed previously, mobile phones contain critical precious metals, and some rare earth materials. These materials are completely wasted if they are landfilled as municipal waste. Currently, therefore, the MRN has a key role to play in the recycling of mobile phones in Japan, as it is the only direct route to recycling.

\subsection{Detailed Material Flow Model}

The MRN data set, however, is not able to confirm how long the mobile phones are in use or the final destination of the used mobile phones after the first collection by MRN and others. It should also be noted that some consumers may try to place their products in recycling bins sometime after having stopped using the mobile once they have salvaged the phones necessary data, in which case hibernation may not be the final destination. The actual material flows of mobile phones can, as a result, be quite complex. Figure 2 is a material flow model of used mobile phones that includes all possible routes after use. Some routes might not be currently feasible, but are considered in order to define the full potential for recycling routes available for mobile phones. The number of each route is defined as the following. 


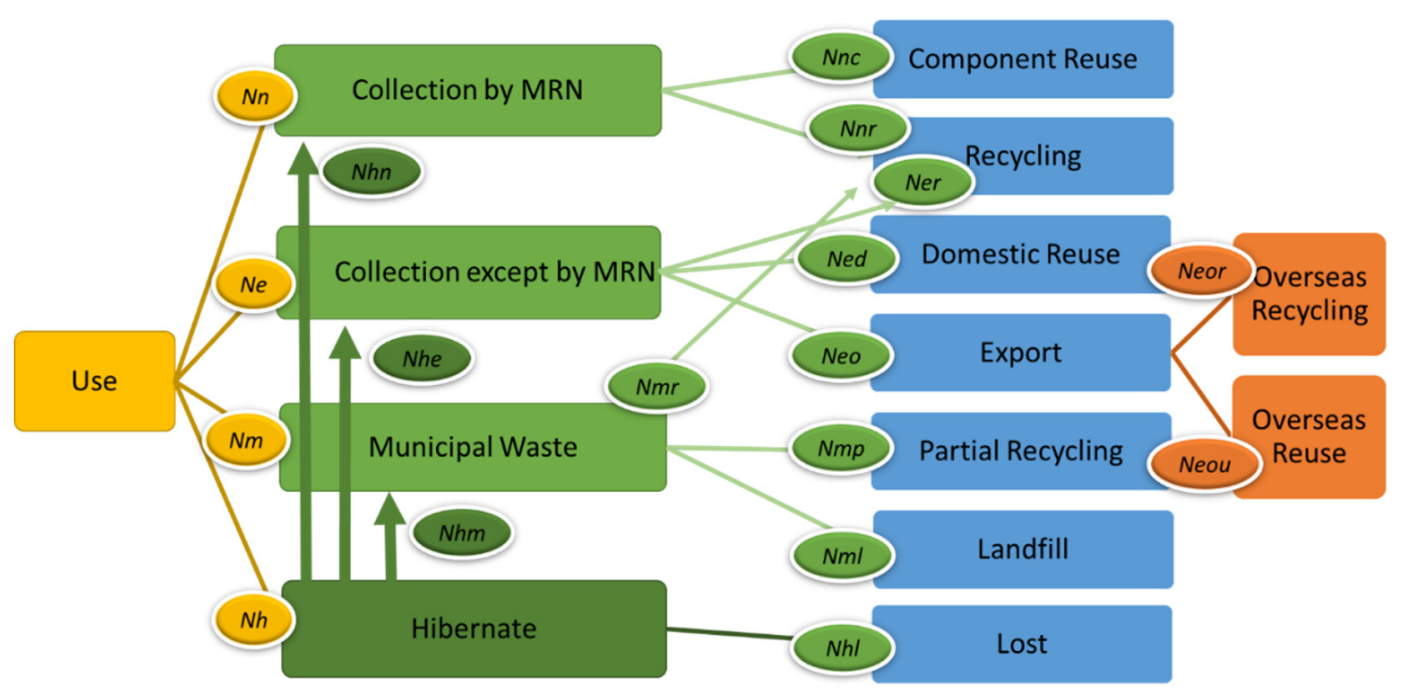

Figure 2. Precise material flow model of used mobile phones. $U_{y}$ : number of mobile phones used per year; $N_{n}$ : number of mobile phones collected by MRN; $N_{e}$ : number of mobile phones collected except by MRN (including undertake); $N_{m}$ : number of mobile phones collected as municipal waste; $N_{\mathrm{h}}$ : number of mobile phones hibernated; $N_{h n}$ : number of mobile phones collected by MRN after hibernation; $N_{h e}$ : number of mobile phones collected except by MRN after hibernation; $N_{h m}$ : number of mobile phones collected as municipal waste after hibernation; $N_{n c}$ : number of mobile phones sent to remanufacturers from MRN; $N_{n r}$ : number of mobile phones sent to recyclers(smelters) from MRN; $N_{e r}$ : number of mobile phones collected except by MRN and domestically recycled; $N_{e d}$ : number of mobile phones collected except by MRN and domestically reused; $N_{e o}$ : number of mobile phones exported; $N_{m r}$ : number of mobile phones collected as municipal waste and sent to recyclers; $N_{m p}$ : number of mobile phones collected as municipal waste and partially recycled; $N_{m l}$ : number of mobile phones collected as municipal waste and landfilled; $N_{h l}$ : number of mobile phones lost; $N_{\text {eor }}$ : number of mobile phones exported and recycled; $N_{\text {eou }}$ : number of mobile phones exported and reused.

\subsection{Quantification of the Flow}

The reuse of mobile phones extends product life and reduces material consumption in both domestic and international mobile phone production. The potential downside to these recycling efforts include the fact that harmless and efficient recycling processes have not been well established in many markets for used mobile phones and the outflow of used electronic products from Japan does result in a need to replace the equivalent amount of materials for new mobile phone production. To quantify Figure 2, surveys [9,17-19] of end-of-life situations of Japanese mobile phones were referred. Assumptions 1 to 7, made in relation to consumer recycling behavior [20], are also included.

1. The consumer will return their used mobile phones to MRN, when they purchase new phones. Thus, $N_{h n}$ is negligible.

2. Once the used mobile phones have been hibernated, independent collectors do not collect (purchase) these products. Thus, $N_{h e}$ is negligible.

3. The amount of flow from non-MRN agencies to recyclers is considered negligible, since non-reusable products will not be undertaken or purchased. Thus, $N_{e r}$ is negligible.

4. Some products will be sent to recyclers from municipal waste. The total of the three major options is 20.2 million units. The difference between this number and the total number of used mobiles is the number of independently recycled mobiles.

5. "Lost" can be assumed that the used products are dumped unconsciously. Thus, $N_{h l}$ should be added to the numbers of municipal waste. 
6. The difference between the number collected by MRN and the number sent to recyclers is equivalent to the number sent from municipal waste to recyclers $\left(N_{m r}\right)$.

7. Used mobile phones collected except by MRN will be domestically reused or exported.

An additional survey [21] of the policies of local government in the handling of small-sized e-waste products highlighted that among 25 Local governments, only 11 of them recover limited materials from municipal waste and put products/materials into the recycling process. When a recycling process of small-sized e-waste depends on hand-pick from waste and recovers only iron and copper, it is assumed that very limited numbers of mobile phones are recycled. Finally, Table 1 reflects all the investigated and assumed data regarding the material flow model of used mobile phones in Japan. The numbers of the phones available in the previous surveys are shown in the table with reference numbers. The other numbers were decided by the above-mentioned assumptions and calculations.

Table 1. Estimated quantitative data of Mobile phone market in Japan [17-19].

\begin{tabular}{|c|c|c|}
\hline Variables & Meaning of the Variables & Amount (Million Units) \\
\hline$N_{n}$ & number of mobile phones collected by MRN & $6.97[17]$ \\
\hline$N_{e}$ & number of mobile phones collected except by MRN (including undertake) & $5.72[18]$ \\
\hline$N_{m}$ & number of mobile phones collected as municipal waste & 7.21 (calculated) \\
\hline$N l$ & Number of mobile phone landfilled & $6.54[18]$ \\
\hline$N_{h n}$ & number of mobile phones collected by MRN after hibernation & 0 (assumed) \\
\hline$N_{h e}$ & number of mobile phones collected except by MRN after hibernation & 0 (assumed) \\
\hline$N_{h m}$ & number of mobile phones collected as municipal waste after hibernation & $0.13[19]$ \\
\hline$N_{n c}$ & number of mobile phones sent to remanufacturers from MRN & 0.02 (calculated) \\
\hline$N_{n r}$ & number of mobile phones sent to recyclers(smelters) & $7.60[18]$ \\
\hline$N_{e r}$ & number of mobile phones collected except by MRN and domestically recycled & 0 (assumed) \\
\hline$N_{e d}$ & number of mobile phones collected except by MRN and domestically reused & $0.14[18]$ \\
\hline$N_{e o}$ & number of mobile phones exported & 5.58 (calculated) \\
\hline$N_{m r}$ & number of mobile phones collected as municipal waste and sent to recyclers & 0.65 (calculated) \\
\hline$N_{m p}$ & number of mobile phones collected as municipal waste and partially recycled & 0.15 (calculated) \\
\hline$N_{m l}$ & number of mobile phones collected as municipal waste and landfilled & $6.54[18]$ \\
\hline$N_{\text {eor }}$ & number of mobile phones exported and recycled & 5.58 in total (calculated) \\
\hline$N_{\text {eou }}$ & number of mobile phones exported and reused & 5.50 in total (calculated) \\
\hline
\end{tabular}

In the next section, we evaluate the different end-of-life options for mobile phone recycling in terms of reducing the material consumption and environmental impacts associated with their production.

\section{Quantitative Analysis of the Material Flow Model}

\subsection{Method of the Analysis}

The purpose of this analysis is to clarify which end-of-life option for used mobile phones results in the best way to reduce the material consumption or environmental impacts associated with mobile phone production depending on the different material flows of the recycling options considered. A coefficient of partial differentiation is used to show how sensitive the final output (amount of material consumption) is to the change of parameters in the material flow model. In clarifying what are the most efficient recycling strategies in detail, including from "increasing the MRN collection rate" to "increasing the domestic reuse rate". Based on the material flow model shown in Figure 2, the amount of material consumption involved in new mobile phone production can be estimated. Whilst the actual material composition of the mobile phones is not considered, differing values are given to the recycling rates assuming a certain percentage in weight of the product will be recycled.

\subsection{Quantification of Matetrial Usage}

If we consider the annual production of mobile phones increases $5 \%$ per year [22] and the average use life is about three years [22], the number of mobile phones in the market after one generation of 
product life can be expressed by Equation (1). Equation (2) represents the total material consumption in mobile phone production. Obviously, total mobile production can be increased by reducing the proportion of mobiles recycled. It is also assumed that not every phone can be reused and not all of the mobile phone material by weight can be recycled. A "recycling rate" $\left(R_{r}\right)$ has been defined. It is also assumed that not every mobile phone component can be reused [23]. A reuse rate for these components is defined $R_{c}$, with the balance of component materials put into the material recycling process. Used products sent to municipal waste landfill are also assumed to include some limited recycling potential for the recovery of iron and copper. This landfill recycling process rate is defined as $R_{p r}$.

As the majority of mobile phones used in the Japanese market are imported, the domestic reuse and domestic material recycling rates have an effect on reducing mobile imports. This analysis considers this effect is equivalent to a direct reduction of the total number of mobiles produced. As a result, the annual number of production is expressed by Equation (3).

$$
\begin{gathered}
U_{y+3}=U_{y} \cdot P I^{3} \\
W_{y+3}=N_{y+3} \cdot M \\
N_{y+3}=\left(U_{y+3}-N_{e d}-N_{n c} \cdot R_{c}-\left(N_{n r}+N_{e r}+N_{m r}\right) \cdot R_{r}-N_{m p} \cdot R_{p r}\right)
\end{gathered}
$$

$U_{y}$ : number of mobile phones put into the market in year $y[18]$

PI: production increase rate [22]

$W_{y}$ : weight of material used for mobile phone production in year $y$

$N_{y}$ : number of annual production of year $y$

$M$ : average weight of a mobile phone

$R_{r}$ : material recycling rate

$R_{c}$ : component reusable rate

$R_{p r}$ : partial recycling rate in municipal waste

There are also some end-of-life options for consumers that need to be considered. To express the different consumers' choices available, three independent parameters, the "collection rate by MRN; $R_{n}$," the "collection rate except by MRN; $R_{e}$," and the "municipal waste rate; $R_{m}$ " were defined. Each rate is calculated by dividing the corresponding numbers by the annual output. These consumers' choices are, theoretically, available after the used mobile phones are hibernated. The rate of mobile phones collected by MRN after hibernation, the rate collected by non-MRN agencies after hibernation and the rate dumped as municipal waste to landfill are defined as $R_{h n}, R_{h e}$ and $R_{h \mathrm{~m}}$, respectively.

The practical material flow data show most of the used mobile phones collected by MRN are sent to recyclers directly. However, some can be used for component reuse. The weight ratio of recyclable materials and recoverable components are defined as $R_{n r}$ and $R_{n c}$, respectively.

It is also assumed that a certain proportion of collected mobile phones by non-MRN agencies are domestically reused with the remainder exported. We define the ratio of domestically reused mobile phones by non-MRN agencies as $R_{e d}$. It is expected that some mobiles are sent to recyclers, as not all products will actually be reused. Thus, the ratio of the used products sent to recyclers from non-MRN agencies (independent collectors) is $R_{e r}$.

After collection as municipal waste, some used mobile phones are recovered from the waste and sent to recyclers. Some are put into low-tech recycling processes to recover Iron and Copper. The ratio of those sent to recyclers is defined as $R_{m r}$, and the ratio sent for iron/copper recovery is defined as $R_{m p}$. Using these parameters, and Equations (1) and (2), Equation (3) can be re-written as Equation (4).

The ratios expressing the first end-of-life options such as $R_{n}$, is calculated by dividing the corresponding the number $N_{n}$ by the total number $U_{y}$. Those expressing the second end-of-life 
option such as $R_{h n}$ is expressing the relevant ratio with the previous option. Using these ratios, the numbers in Equation (3) can be expressed as Equations (4) to (9).

$$
\begin{aligned}
N_{e d} & =\left(R_{e}+R_{h e}\right) \cdot R_{e d} \cdot U_{y} \\
N_{n c} & =\left(R_{n}+R_{h n}\right) \cdot R_{n c} \cdot U_{y} \\
N_{h r} & =\left(R_{n}+R_{h n}\right) \cdot R_{n r} \cdot U_{y} \\
N_{e r} & =\left(R_{e}+R_{h e}\right) \cdot R_{e r} \cdot U_{y} \\
N_{m r} & =\left(R_{m}+R_{h m}\right) \cdot R_{m r} \cdot U_{y} \\
N_{m p} & =\left(R_{m}+R_{h m}\right) \cdot R_{m p} \cdot U_{y}
\end{aligned}
$$

By rewriting Equation (3) using Equations (1), (2), (4) to (9), Equation (10) can be obtained. The list of the defined ratios is shown below. Equation (10) represents how each rate of recycling affects the total amount of material usage in mobile production.

$$
\begin{gathered}
W_{y+3} /(M \cdot U y)=P I^{3}-\left(R_{e}+R_{h e}\right) \cdot R_{e d}-\left(R_{n} \cdot+R_{h n}\right) \cdot R_{n c} \cdot R_{c} \\
-\left(R_{n}+R_{h n}\right) \cdot R_{n r} \cdot R_{r}-\left(R_{e}+R_{h e}\right) \cdot R_{e r} R_{r}-\left(R_{m}+R_{h m}\right) \cdot R_{m r} \cdot R_{r}-\left(R_{m}+R_{h m}\right) \cdot R_{m p} \cdot R_{p r}
\end{gathered}
$$

$R_{n}$ : collection rate by MRN

$R_{e}$ : collection rate except by MRN

$R_{m}$ : municipal waste rate

$R_{n r}$ : sent rate for material recycling from MRN

$R_{n c}$ : sent rate for component reuse from MRN

$R_{h n}$ : collection rate by MRN after hibernation

$R_{h e}$ : collection rate except by MRN after hibernation

$R_{h m}$ : collection rate as municipal waste after hibernation

$R_{m r}$ : rate of used products recovered from municipal waste and sent to recycler

$R_{m p}$ : rate of used products put into a low-tech recycling process

\subsection{Calculation of Matetrial Usage Using Sensitivity Analysis}

Each usage rate was defined in Table 2 as the number divided by the total number of mobile phones in each recycling market. The current values of the flow rates are calculated in Table 2. The other ratios are negligible. Based on these values, a sensitivity analysis is carried out to determine the importance of each recycling parameter in reducing material usage in total mobile phone production. By calculating the partial differential of each parameter in Equation (10), it is possible to determine the value of each parameter in improving the end-of-life options for used mobile phones. In these equations, parameters are set to the values shown in Table $2 . R_{r}, R_{c}$ and $R_{p r}$ are set by previous surveys $[9,17,24]$ and the other ratios were calculated. This analysis helps to suggest the best routes to resource efficiency in examining EOL options for mobile phones in Japan. In order to clarify the properness of the end-of-life options for consumers, two new ratios, $R_{\text {comp }}$ and $R_{\text {reuse, }}$ were introduced. These two ratios express the overall ratios of domestic reuse and component reuse, respectively, and are expressed by the multiple of $R_{n}$ and $R_{\mathrm{nc}}$, and of $R_{\mathrm{e}}$ and $R_{\mathrm{ed}}$, respectively. 
Table 2. Current value of the flow rates.

\begin{tabular}{cc}
\hline Flow Rates & Current Value \\
\hline$R_{n}$ & 0.186 \\
$R_{e}$ & 0.153 \\
$R_{m}$ & 0.193 \\
$R_{n r}$ & 0.997 \\
$R_{n c}$ & 0.003 \\
$R_{e d}$ & 0.025 \\
$R_{\text {eor }}$ & 0.975 (in total) \\
$R_{\text {eou }}$ & 0.089 \\
$R_{m r}$ & 0.020 \\
$R_{m p}$ & 0.891 \\
$R_{m l}$ & 0.008 \\
$R_{h m}$ & $0.7[17]$ \\
$R_{r}$ & $0.3[24]$ \\
$R_{c}$ & $0.1[9]$ \\
$R_{p r}$ & \\
\hline
\end{tabular}

\subsection{Calculation of $\mathrm{CO}_{2}$ Emission}

As was mentioned in the beginning, not only material consumption but also $\mathrm{CO}_{2}$ emission is an important aspect to determine end-of-life strategies. This study also investigated the $\mathrm{CO}_{2}$ emissions associated with the material flow of each recycling strategy. Table 3 shows the variables defined in the previous study by Sugiyama et al. (2015) [25] representing the $\mathrm{CO}_{2}$ emissions associated with each activity in the material flow model. Here, the environmental impacts of other activities such as the refurbishment for reuse and disassembly for component reuse, are assumed to be negligible. Using these variables, the illustrated material flow model shown in Figure 2 and Table 1, is expressed in Equation (11) in terms of their environmental impact. It is assumed that transportation distances are negligible for domestic reuse and component reuse.

Table 3. Defined variables for environmental impact.

\begin{tabular}{|c|c|c|}
\hline & Variable & Corresponding Activity \\
\hline & $\begin{array}{l}E_{t o t a l} \\
E_{p} \\
E_{u} \\
E_{t d} \\
E_{t o} \\
E_{r d} \\
E_{r o} \\
E_{l}\end{array}$ & $\begin{array}{l}\text { Total } \\
\text { Production } \\
\text { Use } \\
\text { Domestic transportation } \\
\text { Overseas transportation } \\
\text { Domestic recycling } \\
\text { Overseas recycling } \\
\text { Landfill }\end{array}$ \\
\hline \multicolumn{3}{|c|}{$\begin{array}{l}E_{\text {total }}=E_{p} \cdot\left(U_{y+3}-\left(R_{e}+R_{h e}\right) \cdot R_{e d} \cdot U_{y}-\left(R_{n}+R_{h n}\right) \cdot R_{n c} \cdot R_{c} \cdot U_{y}-\right. \\
\left.\quad\left(\left(R_{n}+R_{h n}\right) \cdot R_{n r}+\left(R_{e}+R_{h e}\right) \cdot R_{e r}+\left(R_{m}+R_{h m}\right) \cdot R_{m r}\right)\right) \cdot R_{r} \cdot U_{y}- \\
\left.\left(R_{m}+R_{h m}\right) \cdot R_{m p} \cdot R_{p r}\right)+E_{u} \cdot U_{y+3}+E_{t d} \cdot\left(\left(R_{n}+R_{h n}\right) \cdot R_{h r}+\left(R_{e}+\right.\right. \\
\left.\left.R_{h e}\right) \cdot R_{e r}+\left(R_{m}+R_{h m}\right) \cdot R_{m r}\right) \cdot U_{y}+E_{t o} \cdot\left(R_{e}+R_{h e}\right) \cdot\left(1-R_{e r}-R_{e d}\right) \cdot \\
U_{y}+E_{r d} \cdot\left(\left(R_{n}+R_{h n}\right) \cdot R_{n r}+\left(R_{e}+R_{h e}\right) \cdot R_{e r}+\left(R_{m}+R_{h m}\right) \cdot R_{m r}\right) \cdot U_{y} \\
\quad+E_{r o} \cdot\left(R_{e}+R_{h e}\right) \cdot\left(1-R_{e r}-R_{e d}\right) \cdot U_{y}+E_{l} \cdot\left(R_{m}+R_{h m}\right) \cdot R_{m l} \cdot U_{y}\end{array}$} \\
\hline
\end{tabular}

\section{Results and Discussion}

\subsection{Calculation of Material Reduction}

Partial differential equations were calculated for seven parameters $\left(R_{n}, R_{e}, R_{m}, R_{h e}, R_{\text {comp }}, R_{\text {reuses }}\right.$, and $R_{r}$ ) in Equation (10). In order to calculate the sensitivity of material consumption by changing 
"collection rate by MRN" $\left(R_{n}\right)$, partial differential by $R_{n}$ is applied to Equation (10). Then, the effect of the "collection rate by MRN" $\left(R_{n}\right)$ (Equation (12)) is applied. Equations for the other six parameters are shown as Equations (13) to (18). Equation (13) is the partial differential of Equation (10) by $R_{e}$, and so on. Figure 3 is the result of the calculation of seven equations using the current rates shown in Table 3. The bar graph shows the relative effectiveness of increasing each parameter in reducing overall material consumption in mobile phone usage. The effects in reducing material consumptions are shown as positive values.

$$
\begin{gathered}
\frac{\partial\left(W_{y+3} /\left(U_{y} \cdot M\right)\right)}{\partial R_{n}}=-R_{n r} \cdot R_{r}-R_{n c} \cdot R_{c} \\
\frac{\partial\left(W_{y+3} /\left(U_{y} \cdot M\right)\right)}{\partial R_{e}}=-R_{e d} \\
\frac{\partial\left(W_{y+3} /\left(U_{y} \cdot M\right)\right)}{\partial R_{m}}=-R_{m r} \cdot R_{r}-R_{m p} \cdot R_{p r} \\
\frac{\partial\left(W_{y+3} /\left(U_{y} \cdot M\right)\right)}{\partial R_{h n}}=-R_{n r} \cdot R_{r}-R_{n c} \cdot R_{c} \\
\frac{\partial\left(W_{y+3} /\left(U_{y} \cdot M\right)\right)}{\partial R_{\text {comp }}}=-R_{c} \\
\frac{\partial\left(W_{y+3} /\left(U_{y} \cdot M\right)\right)}{\partial R_{\text {reuse }}}=-1 \\
\frac{\partial\left(W_{y+3} /\left(U_{y} \cdot M\right)\right)}{\partial R_{r}}=-R_{n} \cdot R_{n r}-R_{m} \cdot R_{m r}
\end{gathered}
$$

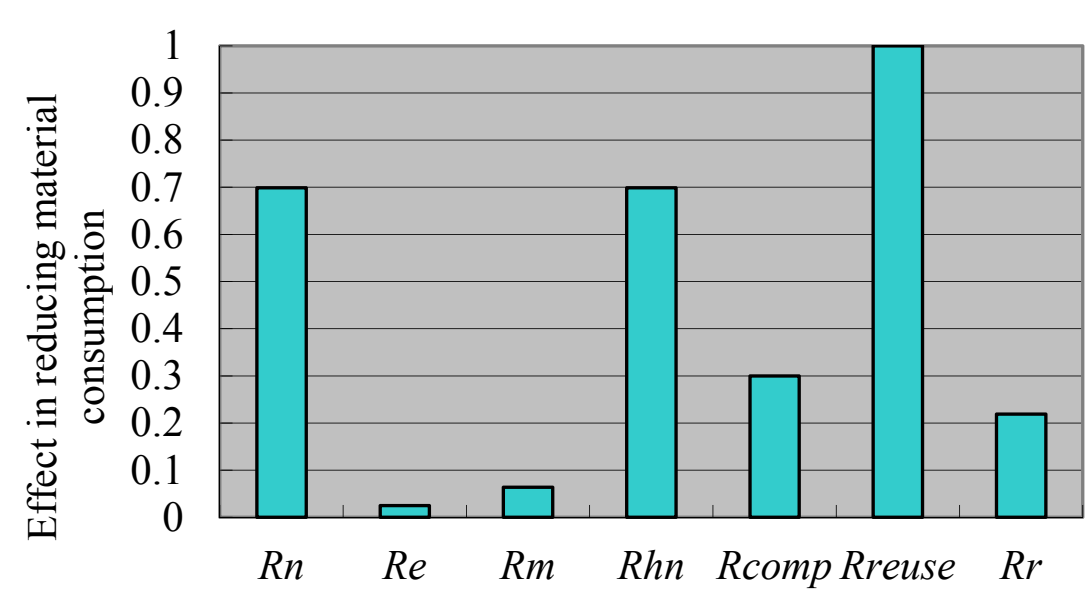

Target Parameters

Figure 3. Effects of end-of-life options on material reduction.

\subsection{Discussion on Material Reduction}

Based on the above analysis of e-waste flow from mobile phone recycling, it is suggested that promoting domestic reuse is the best strategy to reduce the overall material consumption associated with mobile phone usage in Japan, as domestic reuse has a direct effect on reducing the material consumption associated with new production. Material recycling via the official mobile phone recycling network is the second best strategy to reduce mobile phone related resource consumption. As is shown in Equation (14), the effect of increasing collection rate by MRN after hibernation $\left(R_{h n}\right)$ is the same 
as that of collection rate by MRN $\left(R_{n}\right)$. Thus, for material reduction, it is equally good to promote collection of hibernated phones through MRN. In this calculation, the material recycling rate was set at 0.7 from the previous survey [17]. If the material recycling rate is higher than this, then material recycling by the MRN can be a stronger strategy and closer in effectiveness to the domestic reuse option. If the recycling rate is much lower than this value, then product reuse remains the best overall strategy. However, if there is no assurance that the products will be domestically reused, then component reuse could be a better strategy. Based on current end-of-life practices for used mobile phones, strategies to reduce the material consumption associated with the production of mobile phones are suggested below. Whilst the first three strategies are the strongest, 4, 5, 6 and 7 are still potentially viable dependent on individual market, social and technical conditions.

1. Collection of used mobile phones for secondhand use in domestic market.

2. Collection of used mobile phones by the MRN.

3. Collection of hibernated phones by MRN.

4. Collection of used mobile phones for component reuse.

5. Technological development to increase material recycling rate.

6. Collection of used mobile phones for municipal waste landfill.

7. Collection of used mobile phones by non-MRN agencies for any purpose.

Although the technological development to increase the material recycling rate is important, such efforts may not be very effective under current collection rates. Efforts to establish an enhanced system to encourage consumers to put their products in recycling bins is considered very important. Such efforts should be considered first. The results also show that even if the collected mobile phones are dumped in landfill, this option is still better than a mobile phone "lost" in hibernation, since some limited material recycling can be applied to municipal waste. However, this research highlights that proper recycling strategies, such as those involving a network like the MRN, provide much better outcomes in terms of resource efficiency. Developing programs to encourage consumers to increase their efforts to place potentially recyclable manufactured e-waste products like mobile phones in the recycling system, is obviously a clear winner in terms of sustainability outcomes.

\subsection{Calculation of $\mathrm{CO}_{2}$ Reduction}

Values for the environmental impact associated with each of the activities are noted in Table 3 and can be estimated according to a previous study by Takeshima et al. (2006) [26] and an inventory database by the Ministry of Environment (2015) [27], as noted as Table 4.

Table 4. Estimated environmental impact.

\begin{tabular}{cc}
\hline Variable & Environmental Impact (kg-CO $\mathbf{C}$ unit) \\
\hline$E_{p}$ & 43 \\
$E_{u}$ & 1 \\
$E_{t d}$ & negligible \\
$E_{t o}$ & 0.5 \\
$E_{r d}$ & 1.8 \\
$E_{r o}$ & 3.0 \\
$E_{l}$ & 2.7 \\
\hline
\end{tabular}

Using the values shown in Table 4, it is possible to calculate the environmental impacts associated with each end-of-life option. Again, by applying partial differential equations to Equation (11) and the aforementioned seven recycling options, Equations (19) to (25) can be obtained. Using the current value of each ratio indicated in Table 2, the values of the equations are calculated. The results presented 
in Figure 4 show the effects of increasing the seven parameters on reducing $\mathrm{CO}_{2}$ emissions. Again, $R_{\text {comp }}$ is the multiple of $R_{n}$ and $R_{n c}$, and $R_{\text {reuse }}$ is the multiple of $R_{e}$ and $R_{e d}$.

$$
\begin{aligned}
& \frac{\partial\left(E_{\text {total }} / U_{y}\right)}{\partial R_{n}}=-E_{p}\left(R_{n r} \cdot R_{r}+R_{n c} \cdot R_{c}\right)+\left(E_{t d}+E_{r d}\right) \cdot R_{n r} \\
& \frac{\partial\left(E_{t o t a l} / U_{y}\right)}{\partial R_{e}}=-E_{p} \cdot R_{e d}+E_{t d} \cdot\left(R_{e d}+R_{e r}\right)+E_{t o}\left(1-R_{e r}-R_{e d}\right) \\
& +E_{r d} \cdot R_{e r}+E_{r o}\left(1-R_{e r}-R_{e d}\right) \\
& \frac{\partial\left(E_{t o t a l} / U_{y}\right)}{\partial R_{m}}=-E_{p}\left(R_{m r} \cdot R_{r}+R_{m p} \cdot R_{p r}\right)+\left(E_{t d}+E_{r d}\right) \cdot R_{m r}+E_{l} \cdot R_{m l} \\
& \frac{\partial\left(E_{\text {total }} / U_{y}\right)}{\partial R_{h n}}=-E_{p}\left(R_{n r} \cdot R_{r}+R_{n c} \cdot R_{c}\right)+\left(E_{t d}+E_{r d}\right) \cdot R_{n r} \\
& \frac{\partial\left(E_{\text {total }} / U_{y}\right)}{\partial R_{\text {comp }}}=-E_{p} \cdot R_{c} \\
& \frac{\partial\left(E_{/}^{\text {total }} U_{y}\right)}{\partial R_{\text {reuse }}}=-E_{p}-E_{t o}-E_{r o} \\
& \frac{\partial E_{\text {total }}}{\partial R_{r}}=-E_{p}\left(\left(R_{n}+R_{h n}\right) \cdot R_{n r}+\left(R_{e}+R_{h e}\right) \cdot R_{e r}+\left(R_{m}+R_{h m}\right) \cdot R_{m r}\right)
\end{aligned}
$$

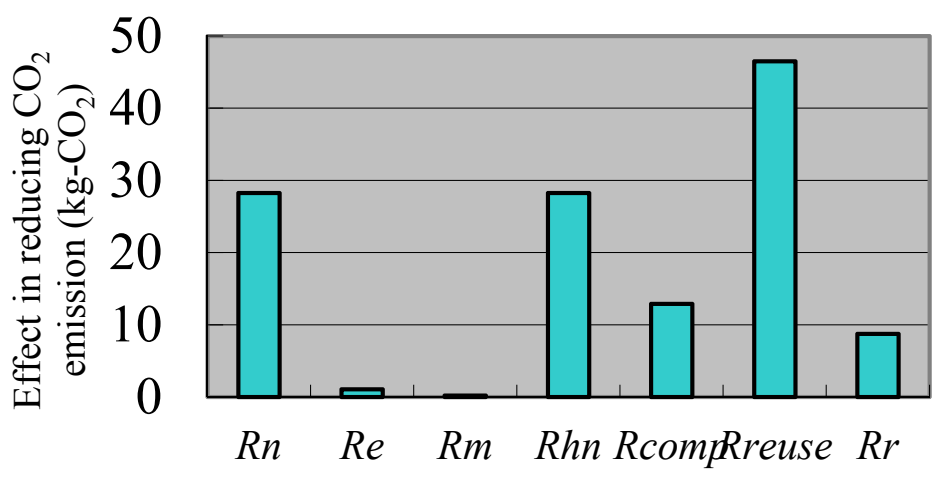

\section{Target Parameters}

Figure 4. Effects of end-of-life options on $\mathrm{CO}_{2}$ reduction.

\subsection{Discussion on $\mathrm{CO}_{2}$ Reduction}

As shown in Figure 4, the general tendency of each parameter to reduce $\mathrm{CO}_{2}$ emissions are very similar to the results presented in Figure 3. A good strategy to reduce material consumption is also a good to strategy to reduce the $\mathrm{CO}_{2}$ emissions associated with reducing the material consumption associated with mobile phone usage. The best strategies are still to increase the domestic reuse rate and enhance material recycling. However, if the purchased product will be reused overseas, the product reuse strategy is not a very good option in terms of improving material consumption efficiency or reducing $\mathrm{CO}_{2}$ emissions. In terms of environmental impact, increasing the material recycling rate is better than increasing the collection rate except when the mobiles are collected by the MRN. Although domestic reuse is a very good end-of-life option, transboundary movements of mobile phones can be a problem. Considering the risk of outflow, an appropriate strategy is to promote material recycling through public recycling networks. 


\section{Conclusions}

Based on a survey of the current end-of-life usage of mobile phones in Japan, a material flow model was used to examine the best strategies for reducing the material consumption associated with mobile phone usage. Since some values were unknown, they were estimated on the basis of qualitative considerations of consumer behavior noted in previous research. Parameters to indicate the rates of different material flows were defined. An equation to calculate the material consumption associated with the production of mobile phones was developed. Since a large proportion of mobile phones are imported into Japan, recycled materials are not directly used for mobile phone production in Japan. However, the overall effect is to both reduce the material consumption associated with mobile phone usage and to extend the life of mobile phones being used. While this research uses a simple assumption that recycled materials contribute to reduce material consumption, this nexus is considered a fundamental parameter in resource efficiency.

In order to determine the relative value of seven different recycling options, "collection rate by the MRN", "collection rate of non-MRN agencies", "municipal waste recycling rate", "collection rate by the MRN after hibernation", "domestic reuse rate", "component reuse rate" and "recycling rate", a sensitivity analysis was carried out.

The results suggest that domestic product reuse and a proper recycling system such as the MRN network are the two most effective strategies in terms of reducing the material consumption associated with mobile phone usage in Japan. It also suggested that efforts to increase the recycling rates of mobile phones given current material flows will require increasing the collection rate of used mobile phones from consumers.

This study also estimated the approximate $\mathrm{CO}_{2}$ emissions associated with the material flow lifecycle of a mobile phone based on previous research studies. These results were similar to the results determined for resource efficiency improvements. The significance of the domestic reuse option was also made clearer when considering associated environmental impact options. Hibernation as an end-of-life option is to be avoided. The significance of establishing proper recycled material collection systems to enhance resource efficiency in end-of-life production systems for mobile phones has been clearly shown in this study. The methodology used in this research has been helpful in indicating which end-of-life strategy is most effective in reducing the material consumption associated with mobile phone usage.

Future research should also consider other strategies, such as prolonging product life, reducing material intensity and reducing product obsolescence timeframes. In addition, it would be useful to apply this method to other countries, since the method is based on modeling and can be carried out even if precise material flow data are lacking. A public organization should be involved in determining end-of-life strategies.

Author Contributions: Kuniko Mishima and Nozomu Mishima formalized the equations of the material flow and carried out the sensitivity analysis of the equation. Michele Rosano reviewed the paper structure, checked English expression and analyzed the calculation results. Nozomu Mishima provided the basic idea to apply sensitivity analysis to the material flow. Hidekazu Nishimura modified the material flow equation to be analyzed and the partial derivatives. Kuniko Mishima wrote the paper.

Conflicts of Interest: The authors declare no conflict of interest.

\section{References}

1. Nanjyo, M. Urban Mine, New Resource for the Year 2000 and Beyond. Bull. Res. Inst. Miner. Dress. Metall. 1998, 43, 239-251.

2. Shiratori, T.; Nakamura, T. Concept of "Artificial Deposit" 2-Transition of the metal potential of spent electric and electronic appliances. J. MMIJ 2007, 4, 171-178. [CrossRef]

3. Halada, K.; Ijima, K.; Shimada, M.; Katagiri, N. A possibility of urban mining in Japan. J. Jpn. Inst. Metals 2009, 73, 151-160. [CrossRef] 
4. Yamane, E.; Minamoto, R.; Numata, T.; Nakajima, K.; Murakami, S.; Daigo, I.; Hashimoto, S.; Okumura, H.; Ishihara, K. Novel Evaluation Method of Elemental Recyclability from Urban Mine-Concept of Urban Ore TMR. Mater. Trans. 2009, 50, 1536-1540.

5. Report of Social Experiment on Promoting Collection of Used Mobile Phones as of Fiscal Year 2009. Available online: http://www.meti.go.jp/meti_lib/report/2010fy01/0020863.pdf (accessed on 20 January 2016). (In Japanese)

6. Murakami, S.; Ohsugi, H.; Murakami-Suzuki, R.; Mukaida, A.; Tsujimura, H. Average lifespan of mobile phones and in-use and hibernating stocks in Japan. J. Life Cycle Assess. Jpn. 2009, 5, 139-145. (In Japanese) [CrossRef]

7. Mishima, K.; Nishimura, H. Requirement Analysis to Promote Small-sized e-waste Collection from Consumers. Waste Manag. Res. 2015. in printing. [CrossRef] [PubMed]

8. Yoshida, A.; Tasaki, T.; Terazono, A. Material flow analysis of used personal computers in Japan. Waste Manag. 2009, 29, 1602-1614. [CrossRef] [PubMed]

9. Murakami, S. Flow Scenarios and Resource Potentials for End-of-life Electric Appliances. Mater. Cycles Waste Manag. Res. 2009, 20, 237-244. [CrossRef]

10. Ministry of Environment, Ministry of Economy, Trade and Industry. Report of Committee for Recycling Systems and Re-Utilization of Valuable Metals in Small-Sized e-Waste. Available online: http://www.env.go.jp/council/former2013/03haiki/yoshi03-24.html (accessed on 20 January 2016). (In Japanese)

11. Case Study on Critical Metals in Mobile Phones Final Report, OECD. 2011. Available online: http://www. oecd.org/env/waste/Case\%20Study\%20on\%20Critical\%20Metals\%20in\%20Mobile\%20Phones.pdf (accessed on 20 January 2016).

12. Soo, V.K.; Doolan, M. Recycling Mobile Phone Impact on Life Cycle Assessment. Procedia CIRP 2014, 15, 263-271. [CrossRef]

13. Duygan, M.; Meylan, G. Strategic management of WEEE in Switzerland-Combining material flow analysis with structural analysis. Resour. Conserv. Recycl. 2015, 103, 98-109. [CrossRef]

14. Neira, J.; Favret, L.; Fuji, M.; Miller, R.; Mahdavi, S.; Blass, V.D. End-of-Life Management of Cell Phones in the United States, Master's of Environmental Science and Management for the Donald Bren School of Environmental Science and Management. Available online: http://www.bren. ucsb.edu/research/documents/cellphonethesis.pdf (accessed on 20 January 2016).

15. Takahashi, K.; Nakamura, J.; Otabe, K.; Tsuruoka, M.; Matsuno, Y.; Adachi, Y. Resource Recovery from Mobile Phone and the Economic and Environmental Impact. J. Jpn. Inst. Metals 2009, 73, 747-751. [CrossRef]

16. G7 Summit Declaration. Available online: http://www.bundesregierung.de/Content/DE/_Anlagen/G8_G20/ 2015-06-08-g7-abschluss-eng.pdf?_blob=publicationFile\&v=5 (accessed on 26 December 2015).

17. Web page of Mobile Recycle Network. Available online: http://www.mobile-recycle.net/ (accessed on 20 January 2016).

18. Web page of Ministry of Economy, Trade and Industry, Material Flow of Used Products. Available online: http://www.meti.go.jp/committee/summary/0003198/pdf/report01_02_02.pdf (accessed on 29 January 2016). (In Japanese)

19. Web page of Polis Department of Tokyo. Available online: http://www.keishicho.metro.tokyo.jp/toukei/bunsyo/ toukei23/pdf/kt23d132.pdf (accessed on 20 January 2016).

20. Telecommunications Carriers Association, Recycling Statistics of Mobile Phones. Available online: http:/ / www.tca.or.jp/press_release/pdf/150623.pdf (accessed 29 January 2016). (In Japanese).

21. Ministry of Economy, Trade and Industry, Case Studies of Small-Sized e-Waste Recycling in Local Governments. Available online: http://www.meti.go.jp/policy/recycle/main/admin_info/committee/o/ 27/hairi27_01-02.pdf (accessed on 29 January 2016). (In Japanese).

22. Internal Affairs and Communications. Available online: http://www.soumu.go.jp/main_content/000299758. pdf (accessed 26 December 2015). (In Japanese)

23. Repro Electric Co. Available online: http://www.reproele.jp/e/ (accessed 5 January 2016).

24. Yamaguchi, H.; Itsubo, N.; Tahara, K.; Inaba, A. Evaluation of $\mathrm{CO}_{2}$ Emissions of Cellurar Phone Manufacturing. 2005. Available online: https://www.jstage.jst.go.jp/article/ilcaj/2005/0/2005_0_9/_pdf (accessed on 20 January 2016). 
25. Sugiyama, K.; Honma, O.; Mishima, N. Quantitative Analysis of Material Flow of Used Mobile Phones in Japan. In Proceedings of the 13th GCSM, Binh-Duong, Vietnam, 16-18 September 2015.

26. Takeshima, A.; Fujinami, T.; Yamada, K.; Nakamura, R.; Yamaguchi, H.; Itsubo, T. LCA including the disposal and recycling stages of a mobile telephone. In Proceedings of the 2nd Conferene of the Institute of Life Cycle Assessment Japan, Tsukuba, Japan, 14-15 November 2006.

27. LCA Inventory Database by Ministry of Environment. Available online: http://www.env.go.jp/ earth/ondanka/supply_chain/com04/ref02.pdf (accessed on 5 January 2016).

(C) 2016 by the authors; licensee MDPI, Basel, Switzerland. This article is an open access article distributed under the terms and conditions of the Creative Commons by Attribution (CC-BY) license (http://creativecommons.org/licenses/by/4.0/). 